\title{
Measurable residual disease in multiple myeloma: ready for clinical practice?
}

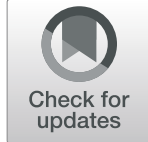

\author{
Leire Burgos ${ }^{1}$, Noemi Puig ${ }^{2}$, Maria-Teresa Cedena ${ }^{3}$, María-Victoria Mateos ${ }^{2}$, Juan José Lahuerta ${ }^{3}$, Bruno Paiva ${ }^{1}$ and \\ Jesús F. San-Miguel ${ }^{1 *}$ (D)
}

\begin{abstract}
The landscape of multiple myeloma (MM) has changed considerably in the past two decades regarding new treatments, insight into disease biology and innovation in the techniques available to assess measurable residual disease (MRD) as the most accurate method to evaluate treatment efficacy. The sensitivity and standardization achieved by these techniques together with unprecedented rates of complete remission (CR) induced by new regimens, raised enormous interest in MRD as a surrogate biomarker of patients' outcome and endpoint in clinical trials. By contrast, there is reluctance and general lack of consensus on how to use MRD outside clinical trials. Here, we discuss critical aspects related with the implementation of MRD in clinical practice.
\end{abstract}

Keywords: Myeloma, Plasma cells, MRD, Clinical practice, Surrogate

\section{Introduction}

The outcome of patients with multiple myeloma (MM) has improved significantly in the last 20 years. This was the result of more than eight novel agents incorporated into the treatment armamentarium of MM, which led to unprecedented rates of complete remission (CR) and prolonged survival. In fact, we are now in a position to discuss whether MM may become a curable disease, which was beyond imagination a few years ago. Eradicating all tumor cells is a prerequisite to cure most malignancies, which raises the need of using high-sensitive tools to evaluate treatment efficacy. Although the definition of $C R$ in $M M$ is very useful in clinical practice, its sensitivity is suboptimal in many patients since current criteria relies on traditional techniques such as serum immunofixation and plasma cell (PC) enumeration by morphology that does not discriminate between normal and tumor cells. Adding immunohistochemistry or

\footnotetext{
* Correspondence: sanmiguel@unav.es

Clínica Universidad de Navarra, Centro de Investigación Médica Aplicada (CIMA), Instituto de Investigación Sanitaria de Navarra (IDISNA), CIBER-ONC number CB16/12/00369, Pamplona, Spain

Full list of author information is available at the end of the article
}

immunofluorescence does not improve cytological analysis and its sensitivity is low $\left(10^{-2}\right)$ due to the recovery of normal PCs after therapy that normalize kappa/ lambda ratios. Furthermore, the serum free light-chain ratio has proven to be of limited value to discriminate patients in $\mathrm{CR}$ at different risk of progression and in fact, the stringent $\mathrm{CR}$ definition has failed to improve riskstratification beyond conventional CR [1-3]. Therefore, the words "complete"-"remission" are misleading for many patients because they may interpret that, once achieved such status, the disease has been eradicated. Thus, it becomes evident that more sensitive techniques are needed to detect measurable (formerly called minimal) residual disease persisting below CR. Ideally, this would contribute to evaluate treatment efficacy with exquisite resolution (one that matches the high efficacy of new regimens) and to avoid both over and under treatment. Unfortunately, there is still a marked imbalance between the extraordinary therapeutic progress and the use of laboratory tests to monitor patients and, accordingly, to individualize treatments decisions in MM.

If response to therapy is one of the most, if not the most, effective marker to predict survival, who would 
not want to know with high precision, the quality of patients' response to therapy? Should we ignore biological information with clear correlation with outcome?. We are now in 2020, but almost 20 years ago there was already evidence about the prognostic impact of persistent MRD in CR patients; should we wait for another two decades or should we implement this information to investigate innovative therapeutic interventions and to individualize patients' management?

MRD techniques can be divided into those identifying extramedullary disease (e.g., positron emission tomography/computed tomography (PET/CT)) and those detecting intramedullary disease by either multiparameter flow cytometry (MFC) immunophenotyping or molecular assessment of immunoglobulin gene rearrangements. Using MFC, we can identify myelomatous PC based on light-chain clonality of phenotypically aberrant tumor cells. Initial MFC approaches (with a sensitivity of $10^{-4}$ and no standardization) $[4,5]$ have evolved into nextgeneration flow (NGF) cytometry developed by EuroFlow, which is based on optimized monoclonal antibodies combinations and sample preparation protocols that overcome blocking or internalization of monoclonal antibodies targeting PC antigens such as CD38, the acquisition of $\geq 10^{7}$ nucleated cells per sample, and novel software tools allowing for automated analysis with an expected sensitivity of $2 \times 10^{-6}$ [6]. A similar evolution was observed on molecular grounds, where clonal immunoglobulin gene rearrangements (the unique ID of myelomatous PC) were initially identified by laborious and low-applicable ASO-PCR techniques and are now detected by next-generation sequencing (NGS) that performs millions of reads of DNA fragments in a standardized fashion with a sensitivity of $10^{-6}$ [7]. Both NGF and NGS have advantages and disadvantages for MRD detection that have been enumerated elsewhere $[8,9]$, but yield similar clinical results $[10,11]$ if used according to the guidelines of the International Myeloma Working Group (IMWG) [9]. NGS has been standardized through commercial kits developed by some companies and can be performed in frozen samples, which is an advantage for large multicenter clinical trials; NGF does not require baseline samples, allows evaluation of the whole bone marrow (BM) cellularity (e.g., hemodilution) and results are available in few hours. While both NGF and NGS supersede the performance of previous immunophenotypic and molecular methods, patients with undetectable MRD by any of these technologies continue to show a linear risk of relapse [12]. Thus, further improvement in the sensitivity of NGF and NGS are warranted to optimize risk-stratification based on patients' MRD status. PET/CT is currently the optimal method to evaluate the disease outside the BM and there are ongoing efforts for its standardization [13]. Fluorodeoxyglucose is the most widely used radiolabeled compound but others such as methionine are under investigation [14]. PET/ CT evaluation of treatment efficacy correlates with patients' PFS [15-17]. Furthermore, studies from the IFM and University of Arkansas demonstrated complementarity between PET/CT and flow cytometry for riskstratification [16, 18]. A recent analysis of PETHEMA/ GEM uncovered that approximately half of patients with undetectable MRD developing early progression, some of them with extra-osseous plasmacytomas at diagnosis, presented new plasmacytomas as an isolated criterion of disease progression, without detectable M-protein or BM infiltration. Thus, it appears that these were true false-negative MRD results, reinforcing the need to combine NGF or NGS with PET/CT to monitor treatment efficacy, particularly in patients presenting with extramedullary or macro-focal disease, as well as elevated LDH levels [19].

Here, we will discuss critical aspects related with the implementation of MRD in clinical practice.

\section{Does undetectable MRD meet the key requirements to be used as treatment endpoint?}

We considered the following prerequisites to evaluate if undetectable MRD can be used as treatment endpoint in MM: (1) must supersede the prognostic value of CR; (2) must provide reproducible results irrespectively of methodology and disease setting; and (3) must be applicable to all patients.

\section{MRD supersedes CR}

Many studies have shown significant differences in progression-free (PFS) and overall survival (OS) between patients in CR with detectable vs undetectable MRD, and this was confirmed in a recent meta-analysis showing a hazard ratio (HR) of $0.44(95 \% \mathrm{CI} 0.34-0.56, P<$ $.001)$ for PFS and of 0.47 (95\% CI $0.33-0.67, P<.001$ ) for OS in favor of those patients in CR who had undetectable MRD [20]. Another striking evidence that MRD supersedes CR is the study conducted by Lahuerta et al. [21] in a large MM series (797 cases). First, it was demonstrated that patients in CR have longer PFS and OS than those in very good partial response (VGPR)/ near complete response (nCR), partial response (PR) or less than PR. However, upon discriminating patients in CR that were MRD negative and positive, it became evident that cases in CR with persistent MRD had the same outcome as patients in nCR/VGPR and even PR (PFS of 27 and 29 months, and OS of 59 and 65 months, respectively). These results underpin that the true value of $\mathrm{CR}$ is intimately connected to the subset of patients in $\mathrm{CR}$ that have undetectable MRD: the higher the frequency of undetectable MRD the better the outcome of CR patients [21]. 
The clinical impact of MRD is reproducible in different centers, by molecular and immunophenotypic methods, and in all disease settings

Recent studies in the transplant setting have reported groundbreaking results using NGS and NGF [19, 22]. With a sensitivity in the logarithmic range of $10^{-6}$, both provided similar and dramatic discrimination between patients with undetectable vs persistent MRD, which resulted in HR for PFS of 0.22 (95\% CI $0.15-$ $0.34 ; P<.001)$ with NGS and 0.18 (95\% CI $0.11-$ $0.30 ; P<.001)$ with NGF. This confirms that both techniques are equally robust for risk-stratification and illustrates the reproducibility between different centers/groups regarding clinical outcomes according to MRD results. Indeed, a subanalysis of the CASSIOPEIA study conducted by the French group that compares both techniques at the sensitivity level of $10^{-5}$, showed high correlation [10]. Large studies such as the UK Myeloma XI [23] and the EMNO2/MO95 [24] conducted by other centers/groups that used MFC with a sensitivity ranging from $10^{-4}$ to $10^{-5}$, were able to reproduce the prognostic impact of MRD (HR for PFS of 0.19 and 0.44, respectively).

Until recently, information in transplant-ineligible patients was less abundant probably because achieving CR was infrequent in this setting. Two large randomized trials comparing VMP or Rd with or without daratumumab (ALCYONE and MAIA, respectively) demonstrated that independently of treatment, those patients achieving undetectable MRD by NGS enjoyed significantly longer PFS $[25,26]$. Similar results were described in the CLARION trial using NGF [27]. Of note, the Spanish group has shown that the impact of MRD negativity in reducing the risk of progression and/or death is higher in the elderly as compared to transplant-eligible patients [21]. We believe this reflects the impact of initial depth of response in a patient population with limited options to receive more than 2-3 lines of therapy due to age and comorbidities [28]. New options for salvage therapy have markedly increased depth of response and survival in patients with relapsed/refractory MM. In this setting, the most solid MRD information derives from two randomized studies using NGS: CASTOR (bortezomib/dexamethasone \pm daratumumab) [29] and POLLUX (lenalidomide/ dexamethasone \pm daratumumab) [30]. Both confirmed that irrespective of treatment, MRD-negative patients had significantly longer PFS. Altogether, these results confirm that the clinical value of reaching MRD negativity is independent of the treatment received, which has been reproduced in different studies by different groups using different techniques. This is supported by the meta-analysis of Munshi et al. [20].

\section{Undetectable MRD is clinically relevant in patients with} standard- and high-risk disease

It is well-stablished that MM patients with high-risk cytogenetics have poor outcome. While the achievement of CR commonly fails to prolong survival in this population, the Spanish group showed that the impact of achieving MRD negativity in reducing the risk of progression and/or death is even higher in patients with adverse cytogenetics than in standard-risk cases [19, 21]. The French group has confirmed that MRD status by NGS not only discriminates outcomes in both standardand high-risk patients, but also that if the later population achieve an undetectable MRD their PFS will be longer than those with standard-risk cytogenetics but persistent MRD [22]. Similar results have been reported by NGF [19]; the median PFS was similar for MRDnegative patients with revised International staging system (R-ISS) 1, 2, and 3 (not reached in any category), while in the MRD-positive population the median PFS was not reached for R-ISS 1 , and it is 38 months and 14 months for R-ISS 2 and 3, respectively. These results reinforce the predictive value of MRD in standard and high-risk MM and unveil that risk is dynamic, since patients with adverse prognosis may shift into favorable once upon achieving deep responses to treatment with undetectable residual tumor cells [19]. These findings suggest that the only way to overcome the dismal outcome of high-risk patients is by considering undetectable MRD as their treatment endpoint.

\section{Potential pitfalls of MRD in MM}

All the above suggests that MRD meets the key requirements to become a treatment endpoint in MM. However, the potential pitfalls of MRD techniques should be recognized and have been summarized below in four items:

\section{The quality of BM samples}

MM displays a patchy pattern of $\mathrm{BM}$ infiltration and, irrespectively of that, samples can be hemodiluted. Accordingly, we cannot be totally certain that an MRDnegative result, irrespectively of the technique used, represents real absence of clonal PC or is due to sampling error. To minimize a false MRD-negative result, the presence of BM cellular elements should be evaluated [6] and an MRD-negative result should be confirmed in a second (or more) assessment [9].

\section{Patients displaying transient or unsustained MRD negativity}

In line with what is required for definition of CR (a confirmatory sample), for MRD it has become evident that although MRD negativity in a single time point clearly predicts longer survival, risk-stratification is significantly 
improved when this result is reproduced at 6 or 12 months. (POLLUX and CASTOR studies [31]).

\section{Cases remaining MRD positive at very low levels without disease progression}

This may be explained by the presence of "benign" MRD clones and/or a very active immune reconstitution with the capacity to control low numbers of residual clonal cells [28]. The Spanish group and others have shown a few patients with unique immune features may have prolonged PFS despite persistent MRD [28, 32].

\section{Persistence of extramedullary disease not detectable in BM aspirates}

The extended use of PET/CT in MM assessment has illustrated that not only extramedullary, but also paramedullary and single focal lesions can be present and undetectable with conventional MM exams [33]. In fact, there is now consensus that evaluation, both inside and outside the BM, is the best option to detect residual disease, and patients that are double negative for these two complementary assessments have the best outcome $[9,18]$.

\section{How to implement MRD in clinical practice?}

Since MRD is one of the most (if not the most) relevant prognostic factor, we should take advantage of this information to improve patient management (including both for innovative clinical trial-e.g., Table 1-design and in clinical practice). Naturally, MRD assessment should be performed only when a BM aspirate is collected to confirm CR, in accordance to the IMWG guidelines [9]. From thereafter, MRD testing should be performed whenever such results could help on clinical decisions (e.g., in between treatment stages) and repeated periodically (e.g., every 1 or 2 years) to confirm patients' MRD status. First, it is important to clarify that while, as discussed above, an MRD-negative result still has a certain degree of uncertainty, persistence of MRD is a strong adverse prognostic feature, even among CR patients. Accordingly, it will be safer to make clinical decisions based on persistent MRD than on undetectable MRD.

How to take advantage of the higher sensitivity of modern MRD techniques to evaluate treatment efficacy and to guide therapeutic decisions? Table 1 shows the ongoing clinical trials that use MRD assessment using next-generation techniques. As a first example, if a patient is in CR before ASCT, how to evaluate the efficacy of subsequent high-dose therapy? In this context, you may be guided by the effect of high-dose therapy on persistent MRD. Similarly, if the patient is reluctant or is not a candidate for ASCT and has achieved CR, why not continue with additional cycles of consolidation until MRD becomes undetectable before moving to maintenance? Second, in high-risk patients with persistent MRD following an optimized induction plus ASCT, we know median PFS will be very short (typically less than two years) [21, 22]; accordingly, it could be envisioned that the introduction of novel agents such as monoclonal antibodies plus second/third generation of PI/IMIDS after ASCT may produce benefit; noteworthy, this "riskadapted therapy approach" is being tested in some trials. Third, if we know that treatment " $\mathrm{A}$ " induces three-fold higher MRD-negative rates as compared to treatment "B," should this influence my clinical practice? Fourth, to adapt maintenance intensity and duration. Several clinical trials are investigating this concept; for example, the RADAR study from the UK group segregates MRDpositive and MRD-negative patients after ASCT: in the first cohort, they will compare 1 vs 2 vs 3 drugs (IMIDPI-MoAb), while in MRD-negative cases, they will explore treatment until disease progression versus fixed duration. Similarly, in the Spanish GEM2014MAIN trial, after 2 years maintenance patients were randomized according to MRD: if positive, they continued for 3 years but if negative, they stopped treatment [19]. These are selected examples out of many other trials with similar conceptual design, all oriented to stop maintenance if the patient is MRD-negative and continue if positive. However, it can be argued that if patients remain MRDpositive after optimal intensive treatment (including 3-4 drugs), maintenance with a single agent will be of limited value and probably, these cases may benefit from an experimental approach (e.g., individualized immunotherapy according to tumor and immune cell biology). By contrast, if patients have undetectable MRD, standard maintenance approaches may effectively maintain immune surveillance and sustain undetectable MRD for long periods of time. Accordingly, data from most recent studies suggest that patients with undetectable MRD are the ones that (as opposed to cases with persistent MRD) benefit the most from maintenance therapy $[19,22,25$, 26]. We believe this is the surrogate biomarker of cure in MM, and trials designed to address these concepts are of utmost importance (Table 1). In fact, the notion that MRD can act as surrogate biomarker for survival and thereby accelerate drug development is evolving based on consistent and positive results observed in recent years (Table 2), and a progressive number of clinical trials are using MRD rates as primary endpoint (Fig. 1).

\section{Looking into the future}

The longer an undetectable MRD status is sustained, the higher its impact in reducing the risk of progression and prolonging survival of MM patients. This requires periodic MRD assessment and invasive BM aspirates pose a challenge. Thus, further methodological innovation is warranted to monitor MRD in blood as frequent as possible. Of note, promising results have been recently 
Table 1 Clinical trials where MRD guides treatment decisions. Results are based on a search in the 'https://clinicaltrials.gov/' website that included the terms "multiple myeloma" and "MRD", and individual identification of clinical trials where treatment algorithms were triggered by patients' MRD status. Selected studies (identified with an asterisk) were added based on knowledge of their existence, despite being absent in search results. It should be noted that many more studies assess MRD and in most clinical trials, MRD response rates are a primary or secondary endpoint (see Fig. 1). However, because no apparent treatment decision is being made based on patients' MRD status, those studies were not included in the table below. There are many clinical trials that, to the best of our knowledge, will have MRD-guided treatment decisions but were not added because their design is still being finalized or have not been initiated at the time of this publication

\begin{tabular}{|c|c|c|c|}
\hline NCT & Study official title & Country & Technique \\
\hline NCT02406144 & $\begin{array}{l}\text { Maintenance treatment with lenalidomide and dexamethasone versus lenalidomide, dexamethasone and } \\
\text { ixazomib after autologous hematopoietic stem cell transplantation in patients With newly diagnosed } \\
\text { symptomatic multiple myeloma-duration of maintenance guided by MRD status (GEM2014MAIN) }\end{array}$ & Spain & NGF \\
\hline RADAR* & $\begin{array}{l}\text { Risk adapted therapy directed according to response comparing treatment escalation and de-escalation } \\
\text { strategies in newly diagnosed patients with multiple myeloma suitable for stem cell transplantation }\end{array}$ & UK & N/A \\
\hline NCT03490344 & $\begin{array}{l}\text { Short course daratumumab in minimal residual disease (MRD) positive myeloma patients after } \\
\text { induction therapy with/without consolidative high-dose chemotherapy/autologous stem cell support }\end{array}$ & USA & FC \\
\hline NCT03224507 & Monoclonal antibody-based sequential therapy for deep remission in multiple myeloma (MASTER) & USA & NGS \\
\hline NCT03742297* & $\begin{array}{l}\text { Induction therapy with bortezomib-melphalan and prednisone (VMP) followed by lenalidomide and } \\
\text { dexamethasone (Rd) versus carfilzomib, lenalidomide, and dexamethasone (KRd) plus/minus daratumumab, } \\
18 \text { cycles, followed by consolidation and maintenance therapy with lenalidomide and daratumumab: } \\
\text { phase III, multicenter, randomized trial for elderly fit newly diagnosed multiple myeloma patients aged } \\
\text { between } 65 \text { and } 80 \text { years }\end{array}$ & Spain & NGF \\
\hline NCT03697655 & $\begin{array}{l}\text { Pre-emptive daratumumab therapy of minimal residual disease reappearance or biochemical relapse } \\
\text { in multiple myeloma (PREDATOR) }\end{array}$ & Poland & N/A \\
\hline NCT03710603 & $\begin{array}{l}\text { A phase } 3 \text { study comparing daratumumab, VELCADE (Bortezomib), lenalidomide, and dexamethasone } \\
\text { (D-VRd) Vs VELCADE, lenalidomide, and dexamethasone (VRd) in subjects with previously untreated } \\
\text { multiple myeloma who are eligible for high-dose therapy (PERSEUS) }\end{array}$ & EMN & N/A \\
\hline NCT03992170 & $\begin{array}{l}\text { A pilot study on the efficacy of daratumumab in multiple myeloma (MM) patients in >VGPR/MRD-positive } \\
\text { by next-generation flow (DART4MM) }\end{array}$ & Italy & FC \\
\hline NCT02969837 & $\begin{array}{l}\text { Open-label, single-arm, phase } 2 \text { study of initial treatment with elotuzumab, carfilzomib (Kyprolis), } \\
\text { lenalidomide (Revlimid), and low-dose dexamethasone (E-KRd) in newly diagnosed, multiple myeloma } \\
\text { requiring systemic chemotherapy }\end{array}$ & USA & NGS and MFC \\
\hline NCT04071457 & $\begin{array}{l}\text { S1803, phase III study of daratumumab/rHuPH20 (NSC-810307) + lenalidomide or lenalidomide as post- } \\
\text { autologous stem cell transplant maintenance therapy in patients with multiple myeloma (MM) using } \\
\text { minimal residual disease to direct therapy duration (DRAMMATIC study) }\end{array}$ & USA & NGS \\
\hline NCT04096066 & $\begin{array}{l}\text { Carfilzomib-lenalidomide-dexamethasone (KRd) versus lenalidomide-dexamethasone (Rd) in newly } \\
\text { diagnosed myeloma patients not eligible for autologous stem cell transplantation: a randomized } \\
\text { phase III trial }\end{array}$ & Italy & N/A \\
\hline NCT03376477 & $\begin{array}{l}\text { A randomized, double-blind, placebo-controlled phase II trial of an allogeneic myeloma GM-CSF vaccine } \\
\text { with lenalidomide in multiple myeloma patients in complete or near complete }\end{array}$ & USA & NGS \\
\hline NCT04108624 & $\begin{array}{l}\text { A multimodality approach to minimal residual disease detection to guide post-transplant maintenance } \\
\text { therapy in multiple myeloma (MRD2STOP) }\end{array}$ & USA & NGS \\
\hline NCT04221178 & $\begin{array}{l}\text { A single-arm, prospective atudy of maintenance therapy cessation for patients with multiple myeloma } \\
\text { in sustained MRD-negative remissions }\end{array}$ & USA & NGF \\
\hline NCT04140162 & $\begin{array}{l}\text { Phase } 2 \text { study with minimal residual disease (MRD) driven adaptive strategy in treatment for newly } \\
\text { diagnosed multiple myeloma (MM) with upfront daratumumab-based therapy }\end{array}$ & USA & N/A \\
\hline
\end{tabular}

NGS next-generation sequencing, FC flow cytometry, NGF next-generation flow cytometry, N/A not available, EMN European Myeloma Network

reported using NGS [35] and NGF [36] in peripheral blood (PB). Namely, the EuroFlow consortium as recently reported that with NGF, it was possible to detect MRD in PB of $17 \%$ of patients in CR; most importantly, presence of MRD in PB identified a subgroup of patients in CR with dismal outcome (median PFS of 9 months) [37]. Conversely, both studies using NGS and NGF showed that approximately $40 \%$ of patients displayed MRD in BM that was undetectable in PB $[35,36]$. There is also growing evidence supporting circulating tumor DNA (ctDNA) for liquid biopsies in MM. However, this approach suffers from a conundrum between applicability and extent of genetic information: while targeted sequence of a few genes or hotspot mutations is highly applicable, comprehensive whole-exome sequencing of cfDNA is possible in a small number of patients with high ctDNA burden [38-40]. Thus, these approaches do not seem to be powered for sensitive MRD assessment 
Table 2 Prospective randomized clinical trials with MRD assessment using next-generation techniques. These studies were selected based on reported effect of treatment randomization in patients' outcome and MRD negativity rates. Overall, whenever significant differences in MRD rates are observed, these predicted significant differences in outcome

\begin{tabular}{|c|c|c|c|c|}
\hline Study & Treatment & Outcome & MRD assessment & MRD-negative rate \\
\hline \multicolumn{5}{|l|}{ Transplant-eligible } \\
\hline IFM2009 (NCT01191060) [22, 34] & HDT vs RVD & $\begin{array}{l}\text { HDT: median PFS } 50 \mathrm{~m} \\
\text { RVD: median PFS } 36 \mathrm{~m}\end{array}$ & $\operatorname{NGS}\left(10^{-6}\right)^{a}$ & $\begin{array}{l}\text { HDT } 30 \% \\
\text { RVD } 20 \%\end{array}$ \\
\hline CASSIOPEIA (NCT02541383) [10] & D-VTd vs VTd & $\begin{array}{l}\text { D-VTD: } 18 m \text { PFS 93\% } \\
\text { VTD: } 18 m \text { PFS } 85 \%\end{array}$ & $\operatorname{NGF}\left(10^{-5}\right)$ & $\begin{array}{l}\text { D-VTD 64\% } \\
\text { VTD } 44 \%\end{array}$ \\
\hline \multicolumn{5}{|l|}{ Transplant-ineligible } \\
\hline ALCYONE (NCT02195479) [25] & D-VMP vs VMP & $\begin{array}{l}\text { D-VMP: median PFS NR } \\
\text { VMP: median PFS } 18.1 \mathrm{~m}\end{array}$ & $\operatorname{NGS}\left(10^{-5}\right)$ & $\begin{array}{l}\text { D-VMP } 22.3 \% \\
\text { VMP } 6.2 \%\end{array}$ \\
\hline CLARION (NCT01818752) [27] & KMP vs VMP & $\begin{array}{l}\text { KMP: median PFS } 22.3 \mathrm{~m} \\
\text { VMP: median PFS } 22.1 \mathrm{~m}\end{array}$ & $\operatorname{NGF}\left(10^{-6}\right)$ & $\begin{array}{l}\text { KMP } 15.7 \% \\
\text { VMP } 15.5 \%\end{array}$ \\
\hline MAIA (NCT02252172) [26] & DRd vs Rd & $\begin{array}{l}\text { DRd: median PFS NR } \\
\text { Rd: median PFS } 31.9 \mathrm{~m}\end{array}$ & $\operatorname{NGS}\left(10^{-5}\right)$ & $\begin{array}{l}\text { DRd } 24.2 \% \\
\text { Rd } 7.3 \%\end{array}$ \\
\hline \multicolumn{5}{|l|}{ Relapse/refractory } \\
\hline POLLUX (NCT02076009) [30] & DRd vs Rd & $\begin{array}{l}\text { DRd: median PFS NR } \\
\text { Rd: median PFS } 17.5 \mathrm{~m}\end{array}$ & $\operatorname{NGS}\left(10^{-5}\right)$ & $\begin{array}{l}\text { DRd } 22.4 \% \\
\text { Rd } 4.6 \%\end{array}$ \\
\hline CASTOR (NCT02136134) [29] & DVd vs Vd & $\begin{array}{l}\text { DVd: median PFS } 16.7 \mathrm{~m} \\
\text { Vd: median PFS } 7.1 \mathrm{~m}\end{array}$ & $\operatorname{NGS}\left(10^{-5}\right)$ & $\begin{array}{l}\text { DVd } 11.6 \% \\
\operatorname{Vd} 2.4 \%\end{array}$ \\
\hline
\end{tabular}

MRD measurable residual disease, HDT high-dose therapy, $D$ Daratumumab, $V$ Bortezomib, $T$ Thalidomide, $d$ Dexamethasone, $M$ Melphalan, $P$ Prednisone, $K$ Carfilzomib, $R$ Lenalidomide, PFS progression-free survival, $m$ months, NR not reached, NGF next-generation flow, NGS next-generation sequencing

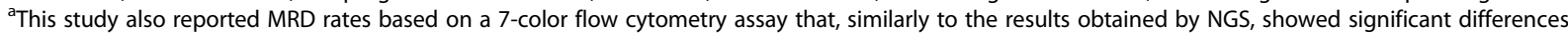
between the HDT vs RVD arm.

in all MM patients. By contrast, matrix-assisted laser desorption ionisation time-of-flight mass spectrometry that detect $M$-proteins in serum has shown to be more sensitive compared to current electrophoretic methods [41, 42]. In fact, most recent observations suggest that this method may provide complementary information to MRD assessment in BM [43, 44]. More studies are needed to define if this concept is ready for prime time. We believe that a minimally-invasive MRD test will foster its use in clinical practice, particularly for preemptive therapeutic approaches upon MRD reappearance in $\mathrm{PB}$. However, at the moment, we consider that $\mathrm{BM}$ remains the gold-standard sample for MRD testing.

We must not forget that under the pressure of enormous drug costs, the best way to make our health systems sustainable is by curing MM. We have experienced great progress and now we need to optimize the use of highly effective drugs developed including emerging

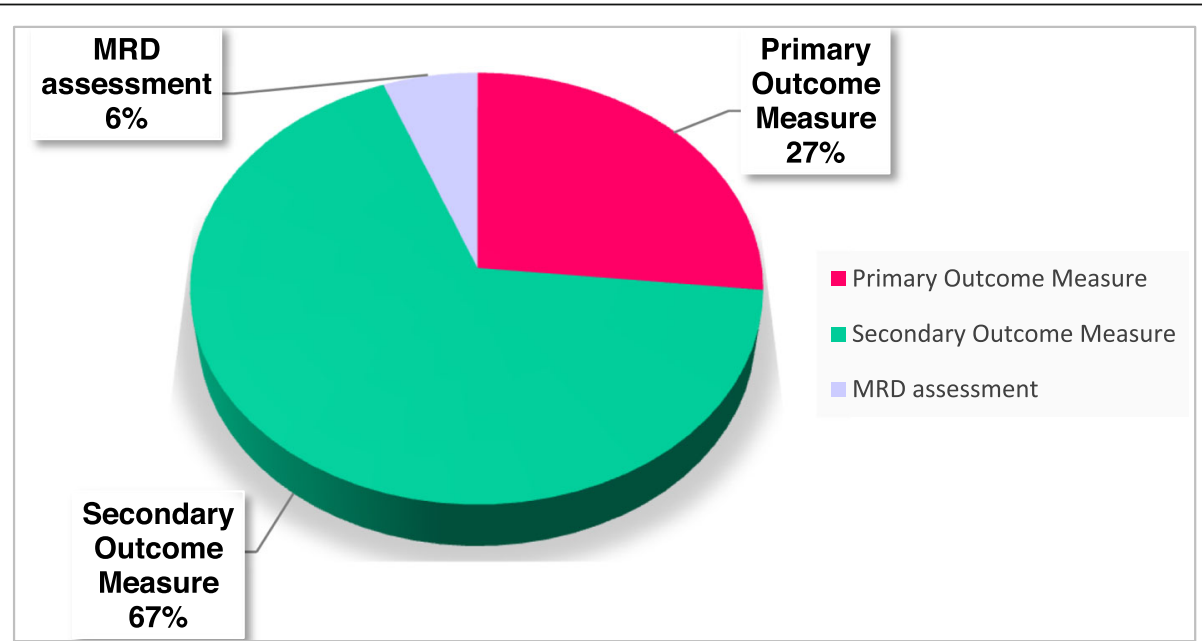

Fig. 1 Clinical trials reporting MRD assessment. Results are based on a search in the https:/clinicaltrials.gov/ website that included the terms "multiple myeloma" and "MRD." Of 170 clinical trials, 154 indicate in the "descriptive information" that MRD is assessed. Furthermore, MRD negative rates are a "primary outcome measure" in 41 (27\%) studies, and a "secondary outcome measure" in 104 (67\%) trials 
immunotherapeuties. This should be implemented early in the course of the disease in order to overcome the poor prognosis of high-risk patients, including those with persistent MRD after optimal frontline treatment. In other words, "early detection of the problem guided by sensitive methods to allow early intervention."

\section{Supplementary information}

Supplementary information accompanies this paper at https://doi.org/10. 1186/s13045-020-00911-4.

Additional file 1. List of investigators in the GEM (Grupo Español de Mieloma)/PETHEMA (Programa para el Estudio de la Terapéutica en Hemopatías Malignas) cooperative study group.

\section{Abbreviations}

MM: Multiple myeloma; MRD: Measurable residual disease; CR: Complete remission; PC: Plasma cell; PET/CT: Positron emission tomography/computed tomography; MFC: Multiparameter flow cytometry; NGF: Next-generation flow; NGS: Next-generation sequencing; IMWG: International Myeloma Working Group; BM: Bone marrow; PFS: Progression-free survival; OS: Overall survival; HR: Hazard ratio; VGPR: Very good partial response; nCR: Near complete response; PR: Partial response; R-ISS: Revised International staging system; PB: Peripheral blood; ctDNA: Circulating tumor DNA

\section{Acknowledgements}

We would like to acknowledge all the investigators in the GEM (Grupo Español de Mieloma)/PETHEMA (Programa para el Estudio de la Terapéutica en Hemopatías Malignas) cooperative study group, which are listed in the supplemental appendix.

\section{Authors' contributions}

L.B., B.P., and J.F.S.M. wrote the manuscrpipt. All authors reviewed, read, and approved the manuscript.

\section{Funding}

Supported by grants from the Centro de Investigación Biomédica en RedÁrea de Oncología-del Instituto de Salud Carlos III (CIBERONC; CB16/12) 00369), Instituto de Salud Carlos III/Subdirección General de Investigación Sanitaria (FIS no. PI15/01956, PI15/02049, FIS PI15/02062 y PI18/01709), Beca Leonardo a Investigadores y Creadores Culturales 2017, Fundación BBVA (IN[17]_BBM_TRA_0236), the Cancer Research UK, FCAECC and AIRC under the Accelerator Award Programme, the Black Swan Research Initiative of the International Myeloma Foundation, and the European Research Council (ERC) 2015 Starting Grant (MYELOMANEXT).

\section{Availability of data and materials}

Not applicable

\section{Ethics approval and consent to participate}

Not applicable

\section{Consent for publication}

Not applicable

\section{Competing interests}

M.-V.M. has received honoraria from lectures or participation in advisory boards from Janssen, Celgene, Amgen, Takeda, Abbvie, Adaptive, GSK, Pharmamar, EDO, Oncopeptides. J.-J.L. reports honoraria from and membership on board of directors or advisory committees with Takeda, Amgen, Celgene, and Janssen. B.P. reports honoraria for lectures from and membership on advisory boards with Amgen, Bristol-Myers Squibb, Celgene, Janssen, Merck, Novartis, Roche, and Sanofi; unrestricted grants from Celgene, EngMab, Sanofi, and Takeda; and consultancy for Celgene, Janssen, Sanofi and Takeda. J.F.S.M. reports consultancy for Bristol-Myers Squibb, Celgene, Novartis, Takeda, Amgen, MSD, Janssen, and Sanofi and membership on board of directors or advisory committees with Takeda. The remaining authors declare no competing financial interests.

\section{Author details}

'Clínica Universidad de Navarra, Centro de Investigación Médica Aplicada (CIMA), Instituto de Investigación Sanitaria de Navarra (IDISNA), CIBER-ONC number CB16/12/00369, Pamplona, Spain. ${ }^{2}$ Hospital Universitario de Salamanca, Instituto de Investigación Biomédica de Salamanca (IBSAL), Salamanca, Spain. ${ }^{3}$ Hospital 12 de Octubre, CIBER-ONC number CB16/12/ 00369, Madrid, Spain.

Received: 7 April 2020 Accepted: 4 June 2020

Published online: 22 June 2020

\section{References}

1. Martínez-López J, Paiva B, López-Anglada L, Mateos M-V, Cedena T, Vidríales $M-B$, et al. Critical analysis of the stringent complete response in multiple myeloma: contribution of sFLC and bone marrow clonality. Blood. 2015;126: 858-62.

2. Lopez-Anglada L, Cueto-Felgueroso C, Rosiñol L, Oriol A, Teruel Al, de la Guia $A L$, et al. Prognostic utility of serum free light chain ratios and heavylight chain ratios in multiple myeloma in three PETHEMA/GEM phase III clinical trials. PLoS One. 2018:13:e0203392.

3. Abdallah N, Kapoor P, Murray DL, Buadi FK, Dingli D, Dispenzieri A, et al. Utility of serum free light chain ratio in response definition in patients with multiple myeloma. Blood Adv. 2020;4:322-6.

4. Rawstron AC, Davies FE, DasGupta R, Ashcroft AJ, Patmore R, Drayson MT et al. Flow cytometric disease monitoring in multiple myeloma: the relationship between normal and neoplastic plasma cells predicts outcome after transplantation. Blood. 2002;100:3095-100.

5. San Miguel JF, Almeida J, Mateo G, Bladé J, López-Berges C, Caballero D, et al. Immunophenotypic evaluation of the plasma cell compartment in multiple myeloma: a tool for comparing the efficacy of different treatment strategies and predicting outcome. Blood. 2002:99:1853-6.

6. Flores-Montero J, Sanoja-Flores L, Paiva B, Puig N, García-Sánchez O, Böttcher $\mathrm{S}$, et al. Next generation flow for highly sensitive and standardized detection of minimal residual disease in multiple myeloma. Leukemia. 2017; 31:2094-103.

7. Faham M, Zheng J, Moorhead M, Carlton VEH, Stow P, Coustan-Smith E, et al. Deep-sequencing approach for minimal residual disease detection in acute lymphoblastic leukemia. Blood. 2012;120:5173-80.

8. Paiva B, Chandia M, Puig N, Vidriales M-B, Perez JJ, Lopez-Corral L, et al. The prognostic value of multiparameter flow cytometry minimal residual disease assessment in relapsed multiple myeloma. Haematologica. 2015;100:e53-5.

9. Kumar S, Paiva B, Anderson KC, Durie B, Landgren O, Moreau P, et al. International myeloma working group consensus criteria for response and minimal residual disease assessment in multiple myeloma. Lancet Oncol. 2016;17:e328-46.

10. Moreau P, Attal M, Hulin C, Arnulf B, Belhadj K, Benboubker L, et al. Bortezomib, thalidomide, and dexamethasone with or without daratumumab before and after autologous stem-cell transplantation for newly diagnosed multiple myeloma (CASSIOPEIA): a randomised, openlabel, phase 3 study. Lancet. 2019;394:29-38.

11. Medina A, Jiménez C, Puig N, Flores-Montero J, Paiva B, Sarasquete ME, et al. Prognostic implications of MRD assessment in multiple myeloma patients: comparison of Next-Generation Sequencing and Next-Generation Flow. Clinical Lymphoma, Myeloma and Leukemia. Elsevier; 2019;19:e47.

12. San-Miguel JF, Paiva B. How deep is the myeloma iceberg? Blood. American Society of Hematology; 2018;132:2424-2425

13. Jamet B, Bailly C, Carlier T, Touzeau C, Nanni C, Zamagni E, et al. Interest of Pet Imaging in Multiple Myeloma. Front Med (Lausanne) [Internet]. 2019 [cited 2020 Mar 2];6. Available from: https://www.ncbi.nlm.nih.gov/pmc/ articles/PMC6465522/

14. Lapa C, Garcia-Velloso MJ, Lückerath K, Samnick S, Schreder M, Otero PR, et al. 11C-methionine-PET in multiple myeloma: a combined study from two different institutions. Theranostics. 2017;7:2956-64.

15. Zamagni E, Nanni C, Mancuso K, Tacchetti P, Pezzi A, Pantani L, et al. PET/CT improves the definition of complete response and allows to detect otherwise unidentifiable skeletal progression in multiple myeloma. Clin Cancer Res. 2015;21:4384-90

16. Moreau P, Attal M, Caillot D, Macro M, Karlin L, Garderet L, et al. Prospective evaluation of magnetic resonance imaging and [18F]Fluorodeoxyglucose positron emission tomography-computed tomography at diagnosis and before maintenance therapy in symptomatic patients with multiple 
myeloma included in the IFM/DFCI 2009 trial: results of the IMAJEM study. JCO. 2017;35:2911-8.

17. Zamagni E, Patriarca F, Nanni C, Zannetti B, Englaro E, Pezzi A, et al. Prognostic relevance of 18-F FDG PET/CT in newly diagnosed multiple myeloma patients treated with up-front autologous transplantation. Blood. 2011;118:5989-95

18. Rasche L, Alapat D, Kumar M, Gershner G, McDonald J, Wardell CP, et al. Combination of flow cytometry and functional imaging for monitoring of residual disease in myeloma. Leukemia. 2019;33:1713-22.

19. Paiva B, Puig N, Cedena M-T, Rosiñol L, Cordón L, Vidriales M-B, et al. Measurable Residual Disease by Next-Generation Flow Cytometry in Multiple Myeloma. J Clin Oncol. 2019;JCO1901231.

20. Munshi NC, Avet-Loiseau H, Rawstron AC, Owen RG, Child JA, Thakurta A, et al. Association of Minimal Residual Disease with Superior Survival Outcomes in patients with multiple myeloma: a meta-analysis. JAMA Oncol. 2017;3:28-35.

21. Lahuerta J-J, Paiva B, Vidriales M-B, Cordón L, Cedena M-T, Puig N, et al. Depth of response in multiple myeloma: a pooled analysis of three PETHEMA/GEM clinical trials. J Clin Oncol. 2017;35:2900-10.

22. Perrot A, Lauwers-Cances V, Corre J, Robillard N, Hulin C, Chretien M-L, et al. Minimal residual disease negativity using deep sequencing is a major prognostic factor in multiple myeloma. Blood. 2018;132:2456-64.

23. de Tute RM, Rawstron AC, Cairns DA, Pawlyn C, Davies FE, Collett C, et al. Impact of minimal residual disease in transplant ineligible myeloma patients: results from the UK NCRI myeloma XI trial. Blood. 2016;128:245.

24. Gambella M, Omedé P, Spada S, Muccio VE, Gilestro M, Saraci E, et al. Minimal residual disease by flow cytometry and allelic-specific oligonucleotide real-time quantitative polymerase chain reaction in patients with myeloma receiving lenalidomide maintenance: a pooled analysis. Cancer. 2019;125:750-60

25. Mateos M-V, Dimopoulos MA, Cavo M, Suzuki K, Jakubowiak A, Knop S, et al. Daratumumab plus Bortezomib, Melphalan, and prednisone for untreated myeloma. N Engl J Med. 2018;378:518-28.

26. Facon T, Kumar S, Plesner T, Orlowski RZ, Moreau P, Bahlis N, et al. Daratumumab plus Lenalidomide and dexamethasone for untreated myeloma. N Engl J Med. 2019;380:2104-15.

27. Facon T, Lee JH, Moreau P, Niesvizky R, Dimopoulos M, Hajek R, et al. Carfilzomib or bortezomib with melphalan-prednisone for transplantineligible patients with newly diagnosed multiple myeloma. Blood. 2019; 133:1953-63.

28. Paiva B, Cedena M-T, Puig N, Arana P, Vidriales M-B, Cordon L, et al. Minimal residual disease monitoring and immune profiling in multiple myeloma in elderly patients. Blood. 2016;127:3165-74.

29. Spencer A, Lentzsch S, Weisel K, Avet-Loiseau H, Mark TM, Spicka I, et al. Daratumumab plus bortezomib and dexamethasone versus bortezomib and dexamethasone in relapsed or refractory multiple myeloma: updated analysis of CASTOR. Haematologica [Internet]. 2018 [cited 2020 Feb 26]; Available from: http://www.haematologica.org/content/early/2018/08/20/ haematol.2018.194118.

30. Dimopoulos MA, Oriol A, Nahi H, San-Miguel J, Bahlis NJ, Usmani SZ, et al. Daratumumab, Lenalidomide, and dexamethasone for multiple myeloma. $\mathrm{N}$ Engl J Med. 2016;375:1319-31.

31. Avet-Loiseau H, San-Miguel JF, Casneuf T, lida S, Lonial S, Usmani SZ, et al. Evaluation of sustained minimal residual disease (MRD) negativity in relapsed/refractory multiple myeloma (RRMM) patients (pts) treated with daratumumab in combination with lenalidomide plus dexamethasone (DRd) or bortezomib plus dexamethasone (D-Vd): analysis of pollux and castor. Blood. 2018;132:3272.

32. Ho CM, McCarthy PL, Wallace PK, Zhang Y, Fora A, Mellors P, et al. Immune signatures associated with improved progression-free and overall survival for myeloma patients treated with AHSCT. Blood Adv. 2017;1:1056-66.

33. Moreau P, Zweegman S, Perrot A, Hulin C, Caillot D, Facon T, et al. Evaluation of the prognostic value of positron emission tomographycomputed tomography (PET-CT) at diagnosis and follow-up in transplanteligible newly diagnosed multiple myeloma (TE NDMM) patients treated in the phase 3 cassiopeia study: results of the Cassiopet companion study. Blood. 2019;134:692.

34. Attal M, Lauwers-Cances V, Hulin C, Leleu X, Caillot D, Escoffre M, et al. Lenalidomide, bortezomib, and dexamethasone with transplantation in myeloma. N Engl J Med. 2017;376:1311-20.
35. Mazzotti C, Buisson L, Maheo S, Perrot A, Chretien M-L, Leleu X, et al. Myeloma MRD by deep sequencing from circulating tumor DNA does not correlate with results obtained in the bone marrow. Blood Adv. 2018;2: 2811-3.

36. Sanoja-Flores L, Flores-Montero J, Garcés JJ, Paiva B, Puig N, García-Mateo A, et al. Next generation flow for minimally-invasive blood characterization of MGUS and multiple myeloma at diagnosis based on circulating tumor plasma cells (CTPC). Blood Cancer J. 2018:8:1-11.

37. Sanoja-Flores L, Flores-Montero J, Puig N, Contreras-Sanfeliciano T, Pontes R, Corral-Mateos A, et al. Blood monitoring of circulating tumor plasma cells by next generation flow in multiple myeloma after therapy. Blood. 2019;134: 2218-22.

38. Lohr JG, Kim S, Gould J, Knoechel B, Drier Y, Cotton MJ, et al. Genetic interrogation of circulating multiple myeloma cells at single cell resolution. Sci Transl Med. 2016:8:363ra147.

39. Manier S, Park J, Capelletti M, Bustoros M, Freeman SS, Ha G, et al. Wholeexome sequencing of cell-free DNA and circulating tumor cells in multiple myeloma. Nat Commun [Internet]. 2018 [cited 2020 Apr 30];9. Available from: https://www.ncbi.nlm.nih.gov/pmc/articles/PMC5923255/.

40. Guo G, Raje NS, Seifer C, Kloeber J, Isenhart R, Ha G, et al. Genomic discovery and clonal tracking in multiple myeloma by cell free DNA sequencing. Leukemia. 2018;32:1838-41.

41. Mills JR, Barnidge DR, Murray DL. Detecting monoclonal immunoglobulins in human serum using mass spectrometry. Methods. 2015;81:56-65.

42. Mills JR, Barnidge DR, Dispenzieri A, Murray DL. High sensitivity blood-based M-protein detection in sCR patients with multiple myeloma. Blood Cancer J. 2017;7:e590

43. Puig N, Mateos M-V, Contreras T, Paiva B, Cedena MT, Pérez JJ, et al. Qipmass spectrometry in high risk smoldering multiple myeloma patients included in the GEM-CESAR trial: comparison with conventional and minimal residual disease IMWG response assessment. Blood. 2019;134:581.

44. Eveillard M, Rustad E, Roshal M, Zhang Y, Ciardiello A, Korde N, et al. Comparison of MALDI-TOF mass spectrometry analysis of peripheral blood and bone marrow-based flow cytometry for tracking measurable residual disease in patients with multiple myeloma. British Journal of Haematology [Internet]. [cited 2020 Apr 30];n/a. Available from: https://onlinelibrary.wiley. com/doi/abs/10.1111/bjh.16443.

\section{Publisher's Note}

Springer Nature remains neutral with regard to jurisdictional claims in published maps and institutional affiliations.
Ready to submit your research? Choose BMC and benefit from:
- fast, convenient online submission
- thorough peer review by experienced researchers in your field
- rapid publication on acceptance
- support for research data, including large and complex data types
- gold Open Access which fosters wider collaboration and increased citations
- maximum visibility for your research: over $100 \mathrm{M}$ website views per year
At BMC, research is always in progress.
Learn more biomedcentral.com/submissions 